\title{
Research of Customer Electricity Consumption Demand Prediction Based on Power Market Econometric Method
}

\author{
Shuo Yin ${ }^{1,2}$, a Meng Yang ${ }^{1,2}$, Hongkun Bai ${ }^{1,2}$, Jiangbo Wang ${ }^{1,2}$, Hujun Li ${ }^{1,2}$ \\ and Dawei Song ${ }^{1,2}$
}

${ }^{1}$ State Grid Henan Economic Research Institute, No.87 Songshan Road, Zhengzhou, China.

${ }^{2}$ Henan Energy Development Research Institute, No.87 Songshan Road, Zhengzhou, China.

a411761498@qq.com

\begin{abstract}
In recent years, influenced by the economic situation, regional industry reporting for expanding capacity growth trend volatility, it is not only a certain effects on the regional power consumption, but also affect the safety of power grid dispatch and operation.Based on the expansion of regional industry reporting for incremental data mining, with the aid of ARMA model, DID econometric methods, research industry expanding new divisions, operating capacity, load utilization, the relationship between the electricity demand and the traditional industry, expanding new prediction method is optimized, and selected a typical area to forecast the regional electricity consumption.
\end{abstract}

Keywords: energy economy; industry reporting for expanding capacity; Econometric analysis; Electricity consumption.

\section{Construction of Power Demand Forecasting Model Based on Big Data Support from Industry Reporting for Expanding Capacity}

\subsection{Data Cleaning}

Cleaning the data on the basis of the marketing system industry reporting for expanding capacity, in the process of data cleaning, the key to eliminate the expansion information of non-production needs, after the completion of the industry reporting for expanding capacity of cleaned data, the user's power data has the appropriate embodiment, To ensure that the use of industry expansion data reflected in the electricity bill after the user to complete the installation.

The key excluded data include:

The reporting for expanding capacity data of application for change of power supply line

The reporting for expanding capacity data of application for dual circuit power access

The reporting for expanding capacity data which repeat the application for a short time.

\subsection{Excluding Non-Expansion Factors}

The influence of electricity consumption is divided into industrial expansion and non industrial expansion. the amount of electricity that is affected by the non-industrial expansion is the total amount of electricity used to eliminate the expansion of the electricity, the comprehensive natural growth rate of non-industrial expansion was carried out by means of ARMA non-industrial expansion prediction method.

The prediction model of ARMA (p, q) non-industrial expansion is the self-regression moving average model, AR is autoregressive, $\mathrm{p}$ is an autoregressive term, MA is moving average, $\mathrm{q}$ is the moving average term.

First, since the regression process AR, let Yt denote the non-expansion capacity of period $t$. If we write Yt model:

$$
Y_{t}-\delta=a_{1}\left(Y_{t-1}-\delta\right)+\mu_{t}
$$

$\delta$ is the mean of $\mathrm{Yt}, \quad \mu_{t}$ is $\mathrm{A}$ random error with zero mean and constant variance, Yt follows a first-order self-regression or AR(1) random process. 
Second, moving average MA, this AR process is not the only possible mechanism for generating Y. If the model $\mathrm{Y}$ is described as:

$$
Y_{t}=\gamma+\beta_{0} \mu_{t}
$$

$\gamma$ is a constant, $\mu_{t}$ is a random error term with zero mean and constant variance. $\mathrm{Y}$ in $\mathrm{t}$ is equal to a constant plus a moving average of the current and past error terms. $\mathrm{Y}$ is said to follow a firstorder moving average or MA (1) process.

Third, the autoregressive moving average process ARMA, if $Y$ has both AR and MA features, it is the ARMA process. $Y$ can be written as:

$$
Y_{t}=\theta+\alpha_{1} Y_{t-1}+\beta_{0} \mu_{t}+\beta_{1} \mu_{t-1}
$$

Where $\theta$ is a constant different from $\gamma . \mu_{t}$ is a random error term with zero mean and constant variance. In the ARMA non-industry expansion forecast model, there are 1 autoregressive and 1 moving average (In this paper, the time series data is 30 periods, satisfying $p=1$ and $q=1$ ), is an ARMA $(1,1)$ process. According to the ARMA model, the non-expansion capacity of the period $t+$ 1 can be predicted by rolling.

\subsection{Sector Expansion Electricity Cycle Calculation}

Reporting for expanding capacity occurred, needs to experience a certain period of electricity, can be completely reflected in the electricity consumption. This article considers the case of new capacity and permanent volume reduction in the next 12 months. According to the industry expansion of the application, delivery time, respectively from the user meter to obtain power for the next 12 months, reporting for expanding capacity the month set as the base month ( 0 months), after each month the power is set to 1-12 months. Different industries due to different industry characteristics, the power cycle is also different, in this paper, the period difference between the month and the month of the month that the load rate tends to be stable after the expansion of the paper is to be used as the receiving cycle, The method of econometric breakpoint regression is used to determine the structural changes of the load rate and the node months that tend to be stable.

Assuming there are $\mathrm{n}$ months before the node month, there are $\mathrm{m}$ months after the node month.

Where: $\mathrm{n}=12-\mathrm{m}$

If there is no structural change in the model, Then the residual sum of squares $R S S_{R}$ of the nmonth sequence before the node month and the residual sum-of-squares $R S S_{U R}$ of the m-month sequence after the node month should not be statistically different, therefore, the original hypothesis (H0) for the two sample regression equation is not statistically significant difference, there is no structural change. On the basis of, the $\mathrm{F}$ test is used to test whether the parameters obtained from the load data of the first $\mathrm{n}$ months and the parameters obtained from the load data of the next $\mathrm{m}$ months are equal, from this to determine whether the structure has changed, the test formula is as follows:

$$
F=\frac{\left(R S S_{R}-R S S_{U R}\right) / k}{R S S_{U R} /(n+m-2 k)}
$$

Where $\mathrm{n}$ is the number of previous months of the node, $\mathrm{m}$ is the number of months after the node, $\mathrm{k}$ is the degree of freedom, judging whether the load factor tends to be stable in the node month by whether the $\mathrm{F}$ value is significant or not.(Whether the $\mathrm{p}$ statistic is greater than 0.5 , if it is greater than 0.5 , it is not a steady load rate node, if it is less than 0.5 , it is a node with a steady load rate)

\subsection{Industry Expansion Loading Rate Change Calculation}

Due to different industry characteristics, the changes in the loading rate of various industries are not consistent, From the perspective of industry segmentation, According to the reporting for expanding capacity data of all users in 52 industries: 


$$
L R\left(I N D, M O N, T Y P_{j}\right)=\frac{\sum_{i=1}^{s} E_{i}}{\sum_{i=1}^{s} A_{i} \times 24 \times 30}
$$

Among them, LR is the reporting for expanding capacity load rate changes, IND is the type of industry; MON is the industry power cycle; TYP is the reporting for expanding capacity application type; $j=1$ for the new equipment, capacity expansion, $j=0$ for the cance account, volume reduction; $\mathrm{E}$ is the user's monthly electricity consumption increase / decrease value, $\mathrm{i}$ is the $\mathrm{i}$-th user in this industry, A for the user to apply for increase / decrease of capacity (TYP is a positive at 1, TYP is a negative at 0 ).

\section{Electricity Consumption based on Econometric Econometric Model.}

\subsection{Cleansing of Electricity data in Henan Province based on the Business Expanding Worksheet in the Marketing System.}

Based on the business expanding worksheet in the marketing system, the data of 52 industries and enterprises in Henan Province from January 2014 to June 2017 were cleaned. In the process of data cleaning, focus on removing industry expansion information which non-production electricity need to apply for. After cleaning, the data of business expanding should be reflected in the user's power data after the installation is complete. To ensure that the use of industry expansion data reflected in the electricity bill after the user to complete the installation. The key excluded data include: the business expanding data of application for change of power supply line, the business expanding data of application for dual circuit power access, the business expanding data which repeat the application for a short time.

\subsection{Energy Econometric Model Set}

Changes in electricity consumption after the expansion of the industry will be affected by a series of external factors such as economy, climate and holidays. On the base of fully consider all the external facotors, ARMA non-expansion model will be used to predict the comprehensive nature growth rate of Henan province electricity industry.

$\operatorname{ARMA}(p, q)$ Non-deployment expansion forecast model is autoregressive moving average model, where AR is autoregressive, $p$ is autoregressive; MA is moving average and $q$ is moving average. The basic idea of ARMA non-expansion forecasting model is that the data sequence formed by nondeployment expansion over time is regarded as a random sequence, and the mathematic model is used to describe the non-expansion sequence. The future value of non-expansion can be predicted from the past and present value of non-expansion.

Henan ARMA non-expansion expansion forecast model is as follows:

$$
Y_{t}=\theta+\alpha_{1} Y_{t-1}+\beta_{0} \mu_{t}+\beta_{1} \mu_{t-1}
$$

Where is a constant different from that of a random error term with zero mean and constant variance. In ARMA non-expansion model, $t=30, p=1$ and $q=1$, that is, there are 1 autoregressive term and 1 moving average term, which is the ARMA $(1,1)$ process. According to the ARMA model, the non-expansion capacity and expansion rate of expansion in $\mathrm{t}+1$ phase can be predicted by rolling.

\subsection{The Forecast of Power Consumption in Henan Province}

A.The estimate of sub-sector business expanding period electricity

After the Business expanding occurred, it needs to experience some of the power cycle, in order to fully reflect the electricity consumption.Consider the expansion of Henan Province, installed capacity within 12 months after the installation of new capacity and permanent capacity reduction account sales situation. According to the business expanding report installments, power transmission time, respectively, from the user meter to obtain the power of the next 12 months, the expansion of 
the installation of business expanding month set as the base month ( 0 months), after the monthly electricity is set to 1-12 month.Different industries due to different industrial characteristics, the power cycle is also different, through the expansion of the load after the installation load ratio tends to be stable in the month and the reference month of the difference between the cycle as the power cycle, through the energy economy break-point regression method to determine the structural changes in the load factor and tends to be stable node month.

Assume that there are $\mathrm{n}$ months before the month of the node month, and $\mathrm{m}$ months after the node month. Among them: $\mathrm{n}=12-\mathrm{m}$

Breakpoint back to the core idea is: if there is no structural change in the model, the nodes in $n$ months before the sequence of $\mathrm{m}$ a month after the month of sum of squared residuals and node sequence of sum of squared residuals on the statistics should not be significantly different, so the original hypothesis $\mathrm{H} 0$ regression equation for the two samples is not significantly different in statistics, namely there is no structural change. On this basis, the use of the F test to test data obtained by the first $\mathrm{n}$ rate on the parameters and the parameters of the data obtained by $m$ months after load rate are equal, thus determine whether structure changed, check formula is as follows:

$$
F=\frac{\left(R S S_{R}-R S S_{U R}\right) / k}{R S S_{U R} /(n+m-2 k)}
$$

Whether the rate of load is stable in the month of the node is measured by $F$ value. The electrografting cycle of 52 industrial sequences in henan province is shown in table 1.

B. Calculation of Load Change Rate of Business Expanding

Due to the different characteristics of the industry, the changing load factor of various industries in Henan is not consistent. From the perspective of industry segmentation, this paper calculates the load rate of business expanding in each industry according to the reporting for expanding capacity of all users in the 52 industries.

$$
L R\left(I N D, M O N, T Y P_{j}\right)=\frac{\sum_{i=1}^{s} E_{i}}{\sum_{i=1}^{s} A_{i} \times 24 \times 30}
$$

LR is the load change rate of reporting for expanding capacity, IND is an industry type; MON represents the industry's receiving cycle; TYP represents the type of expansion application; $j=1$ is newly installed, increase capacity, $\mathrm{j}=0$ is canceling the account, volume reduction; $E$ is the increase / decrease value of user's monthly electricity consumption, $\mathrm{i}$ is the $\mathrm{i}$ 's user of the industry, A is the increased / reduced capacity of users' applications (TYP is a positive at 1 , TYP is a negative at 0 ).

\section{Conclusion}

Under the big background of the economy entering a new normal, there are new features in the power economic relations. Using the analysis methods of business expanding big data econometric, to better grasp the trend of regional electricity demand, service area economic and social development and the safe and stable operation of the power grid. This article is based on the excavation of incremental big data for regional business expanding, using ARMA, DID and other energy econometric simulation analysis methods. At the beginning of the construction of the power demand forecasting model based on the big data supported by the business expanding. Sub-industry research business expanding relationship between the cases, the operating capacity, load utilization and demand for electricity.

\section{Acknowledgments}

This work was financially supported by State grid Science and technology project fund(Research on the electricity market maturity evaluation technology and differentiated operation model of power Grid Company under the new round of electric system reform.5217L017000M). 


\section{References}

[1]. Zhao Yong-liang, Fu Xin. Research on the Monitoring and Analysis of the Sale of Electricity Business Based on Big Data [J], Electric Power Information and Communication Technology, 2016.

[2]. Zheng Haiyan, Xiong Zheng, Ji Cong. Forecasting Method of Electricity Consumption Based on reporting for expanding capacity Big Data[J],Electric Power Information and Communication Technology, 2015.

[3]. Zhang Yu jing, Zhi Qun, Wang Xiao yu, Wang Fang. The Innovative Application of Large Data Platform to Resource Integration and Savings for Power Industry Expansion and Power Generation Plan Compilation [J], Resources Economization \& Environmental Protection, 2016.

[4]. Hui Chen, Zheng, An gang, Zou Heping, Zhang Mi. District Electric Power Comsumption Prediction and Management Simulation [J] Computer Simulation, 2016.

[5]. Yan Wei, Cheng Chao, Xue Bin, Li Dan, Chen Fei. Forecasting for Monthly Electricity Consumption Using X12 Multiplication Method and ARIMA Model [J], Proceedings of the CSU-EPSA, 2016.

[6]. Cao Ming. Dynamic Analysis and Forecast of Energy Economic Efficiency of China [J], China Population Resources and Environment, 2011.

[7]. Li Xiang. Medium and Long-term Electricity Demand Forecasting Method Based on Industry Classification [D], South China University of Technology, 2016.

[8]. Zhang Qiang, Wang Yi, LI Dingrui, Zhu Wenjun. Monthly Electricity Forecast Based on X-12ARIMA Seasonal Decomposition and Annual Electricity Correction[J],Electric Power Construction,2017. 